\title{
Explorative surgery for acute scrotal pain: The importance of patient age, side affected, time to surgery and surgeon
}

\author{
Andrea Fabiani ${ }^{1}$, Massimo Calabrese ${ }^{2}$, Alessandra Filosa ${ }^{3}$, Fabrizio Fioretti ${ }^{1}$, Valentina Maurelli ${ }^{1}$, \\ Michele Scandola ${ }^{4}$, Stefano Noventa ${ }^{5}$, Flavia Tombolini ${ }^{6}$, Francesco Catanzariti ${ }^{1}$, \\ Lucilla Servi $^{1}$, Gabriele Mammana ${ }^{1}$ \\ ${ }^{1}$ Surgery Departement, Section of Urology, ASUR Marche Area Vasta 3, Macerata Hospital, Macerata, Italy; \\ 2 Operative Unit of Urology SS. Filippo e Nicola Hospital, Avezzano (AQ), Italy; \\ ${ }^{3}$ Section of Pathological Anatomy, Department of Clinical Pathology, Area Vasta 3, ASUR Marche, Macerata Hospital, Macerata, Italy; \\ ${ }^{4}$ Departement of Human Sciences, University of Verona - IRCCS Santa Lucia Foundation, Rome, Departement of Psychology, \\ University of Rome "Sapienza", Rome, Italy; \\ ${ }^{5}$ Center for Assessment, University of Verona, Verona, Italy; \\ ${ }^{6}$ Urologic Clinic, Polytechnic University of Marche Region, Italy.
}

\begin{abstract}
Summary Introduction and objective: Testicular torsion must be diagnosed quickly and accurately. The delay of the diagnosis and the subsequent delay of surgery may lead to loss testicular viability and orchidectomy. Aim of our retrospective evaluation was to define which element should be considered as major support to the clinician in distinguishing spermatic cord torsion from the other diseases mimicking this clinical emergency requiring surgical exploration.

Material and methods: We retrospectively reviewed all clinical and instrumental data of emergency scrotal exploration performed for acute scrotal pain at two different Urological Department in a 10 year period. Results of surgical exploration represented the four diagnostic categories in which patients were divided for statistical evaluation. We evaluated the relationship between diagnosis performed by testicular surgical exploration and the all clinical data available including surgeon involved in the procedures.

Results: A total of 220 explorative scrotal surgery were considered. We divided the cases in 4 categories according to the diagnostic results of each surgical procedure. Of all, spermatic cord torsion was diagnosed in $45 \%$ (99/220). The total testis salvage rate was of $78.8 \%$. The patients with a diagnosis of spermatic cord torsion were older than patients with appendix torsion (15 vs 11 years in mean). When the affected side was the left, the probability to have a diagnosis of spermatic cord torsion was higher than the right side $\left[X^{2}(2, N=218)=11.77, p<0.01\right]$. Time elapsing between onset of symptoms and testicular salvagewas significantly lower even than in case of appendix torsion/necrosis $(p<.0001)$, and of others pathologies diagnosed $(p=.0383)$. Conclusion: In case of spermatic cord torsion, in addition to the clinical data, patient age and left side affected may represent an independent diagnostic predicting factor. The time elapsing between onset of symptoms and explorative surgery remain the only still prognostic factor for testicular viability.
\end{abstract}

KEY WORDS: Spermatic cord torsion; Testicular necrosis; Testicular appendages; Scrotal surgery; Doppler ultrasound.

Submitted 1 November 2015; Accepted 4 December 2015

\section{INTRODUCTION}

Acute scrotum is an emergency situation that require a prompt evaluation by physician because of the possibility of loss of the testis in case of misdiagnosed or advanced spermatic cord torsion (1). Without loss of time it is most important, for the often young patients, the immediate etiologic diagnosis of the acute painful swelling of the scrotum. From a clinical point of view, pain is not the only symptom. It is often accompanied with local signs like skin reddening and general symptoms. The diagnoses to be taken into account are several and includes also the torsion of the appendages of testis, inflammatory diseases, like acute epididymo- orchitis, incarcerated inguinal hernia or testicular tumors (2). The spermatic cord torsion requires immediate surgical intervention (3) because the complete testicular ischemia, due to the interruption of blood flow after spermatic cord rotation in longitudinal axis, causes the irreversible loss of organ viability. Therefore, testicular salvage is obtained by efficient and accurately diagnostic tools. In clinical routine the medical history, the clinical evaluation and the ultrasound scrotal scan are the three main diagnostic instrument. Physical examination is often not sufficient to form a diagnosis especially in case of infants patients (4). Ultrasound scan with colorDoppler evaluation is not routinely used by the same radiologists (5). When the investigations are not confident, the surgical exploration begins as both a diagnostic and a therapeutic tool, following the old maxim: "if in doubt check it out". The aim of our retrospective evaluation was to define which type of diagnosis was performed after surgical exploration conducted for an acute scrotal pain in two different Urologic Centers. We compared diagnosis obtained with several clinical factors and instrumental findings in order to define which element should be considered as a major support to the clinician in distinguishing spermatic cord torsion from the other diseases mimicking this clinical emergency requiring surgical exploration. 


\section{MATERIAL AND METHODS}

We retrospectively reviewed all clinical and instrumental data of emergency scrotal explorations performed for acute scrotal pain at two different Urological Department (Macerata Civic Hospital and Avezzano Hospital) in a 10 year period. Over the time period of the study, for the surgical procedures 14 surgeons with a different expertise degree were involved. All patients were evaluated at Emergency Department and then by a consultant Urologist. The same consultant performed the scrotal exploration. Data were obtained from operating theaters notes and patients charts.

They included demographic data like patient age, race, affected side, physical findings, pain duration, results of preoperative ecocolorDoppler ultrasound when performed. The results of surgical exploration represented the four diagnostic categories in which patients were divided for statistical evaluation. We considered the two main causes of acute scrotal pain that can lead to a surgical scrotal exploration, alias spermatic cord torsion (categories 1 and 2) and torsion of the appendix testis (category 3) and we included the others findings in category 4. Category 1 consisted in patients affected by spermatic cord torsion who underwent a radical orchidectomy for testicular necrosis; category 2 included patients who underwent a funicular de-rotation with subdartos orchidopexy because of the conserved vitality of the testis; category 3 was represented by cases of acute scrotum determined by a torsion/necrosis of testicular appendages. We evaluated the relationship between diagnosis performed by testicular surgical exploration and the all clinical data available. Statistical analyses and evaluations were performed by two authors (MS and SN) using $\mathrm{X}^{2}$ test and multiple comparisons between pairs of proportions, corrected according to Bonferroni.

\section{RESULTS}

In our 10-year period of retrospective study, we considered eligible a total of 220 explorative scrotal procedures, 118 performed at Macerata Civic Hospital (Center A), 102 performed at Avezzano Hospital (Center B). We divided the cases in 4 categories according to the diagnostic results of surgical explorations. Demographic data and intra-operative findings are presented in Table 1. Mean patients' age was 14.46 years (range 2-40; standard deviation 0.47 ). No differences were revealed between the two centers. In Center A and B, the mean age was 13.74 (range 4-37; standard deviation 0.56) and 15.29 (range 2-40; standard deviation 0.79 ) years respectively. Of a total of 220 scrotal explorative surgeries, 99 (45\%) were performed for a spermatic cord torsion (categories 1 and
2). In 21 cases $(21.21 \%)$ there was a need to perform a radical orchidectomy because of the loss of testicle viability. In the remnants 78 cases, the procedures consisted in the funicular de-rotation with sub-dartoic orchidopexy. Thus, the total testis salvage rate was of $78.8 \%$ (84\% and $73.46 \%$ for Center A and Center B respectively). Scrotal explorative surgery not confirmed the suspect of spermatic cord torsion in 121 cases revealing the torsion/necrosis of the appendix testis (category 3) in 101 patients and others pathologies (category 4) in the remnants 20 cases ( 15 in Center B). The patients with a diagnosis of spermatic cord torsion were older than patients with appendix torsion, without differences between the two centers. Mean age was 15 years in case of categories 1 and 2 . In contrast, the patients in category 3 were 11 years old in mean (Figure 1). When the affected side was the left, the probability to have a diagnosis of spermatic cord torsion was higher than in case of right side involvement $\left[X^{2}(2, N=218)=11.77, p<0.01\right]$ (Table 2). We noted that appendix testicular torsion/necrosis was diagnosed with significant high frequency in Center A vs Center B $\left[\left(\mathrm{X}^{2}(2, \mathrm{~N}=220)=11.74, \mathrm{p}<0.01, \mathrm{~V}=.231\right]\right.$. Cases in category 4 were most in Center B. In particular,

\section{Figure 1.}

Plot age and diagnosis.

Appendix torsion occur in patients younger than others.

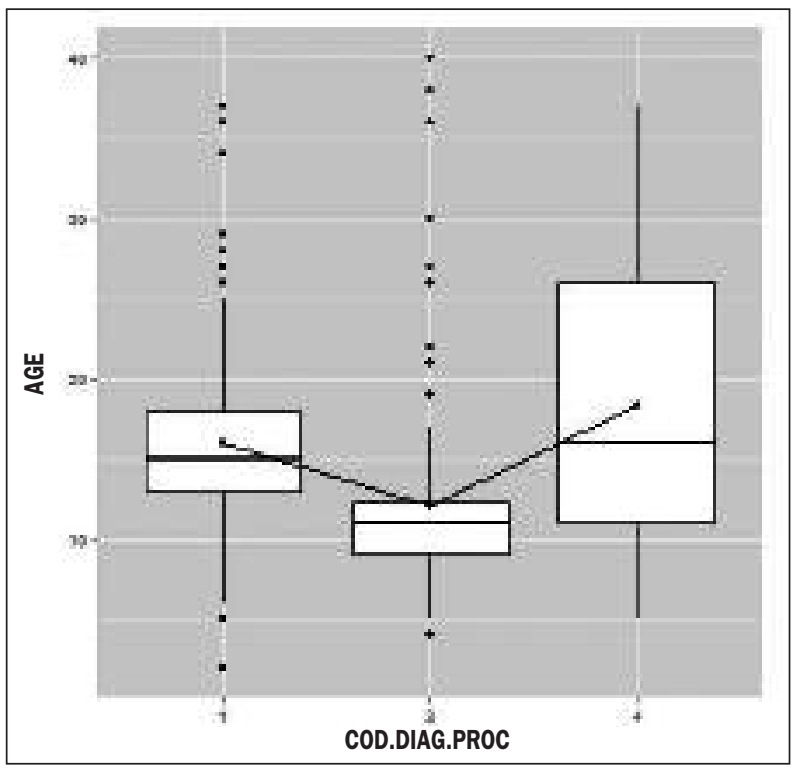

Cod. 1 Spermatic cord torsion

Cod. 2 Appendix torsion/necrosis

Cod. 3 Others pathologies

Table 1.

Demographic data and intraoperative findings of patient in Center A and Center B included in this study.

\begin{tabular}{|c|c|c|c|c|c|c|c|c|c|c|}
\hline & $\begin{array}{l}\text { Patients } \\
\text { (number) }\end{array}$ & $\begin{array}{c}\text { Age } \\
\text { (mean) } \\
\text { in years }\end{array}$ & $\begin{array}{c}\text { Caucasian } \\
\text { Race (n) }\end{array}$ & $\begin{array}{l}\text { Affected } \\
\text { side right } \\
\text { (n) }\end{array}$ & $\begin{array}{l}\text { Affected } \\
\text { side left } \\
\text { (n) }\end{array}$ & $\begin{array}{c}\text { Affected } \\
\text { side bilateral } \\
\text { (n) }\end{array}$ & $\begin{array}{l}\text { Spermatic } \\
\text { cord torsion } \\
\text { with RO (n) }\end{array}$ & $\begin{array}{l}\text { Spermatic cord } \\
\text { torsion with } \\
\text { derotation (n) }\end{array}$ & $\begin{array}{l}\text { Appendix testis } \\
\text { torsion/necrosis } \\
\text { (n) }\end{array}$ & $\begin{array}{c}\text { Echocolor } \\
\text { Doppler ultrasound } \\
\text { performed (n) }\end{array}$ \\
\hline Center A & 118 & 13.74 & 116 & 57 & 59 & 2 & 8 & 42 & 63 & 28 \\
\hline Center B & 102 & 15.29 & 98 & 46 & 56 & - & 13 & 36 & 38 & 102 \\
\hline Total & 220 & 14.46 & 214 & 103 & 115 & 2 & 21 & 78 & 101 & 130 \\
\hline
\end{tabular}


Table 2.

Laterality of testis involved stratified by diagnostic categories.

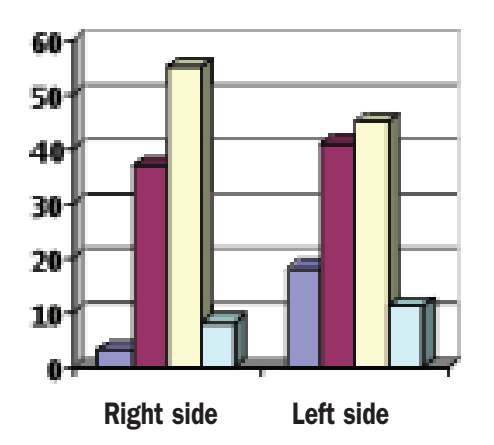

\section{ㅁ Category 1 \\ Category 2 \\ 口 Category 3 \\ Category 4}

\begin{tabular}{|lcc|}
\hline & Right side & Left side \\
\hline Category $\mathbf{1}$ & 3 & 18 \\
\hline Category $\mathbf{2}$ & 37 & 41 \\
\hline Category $\mathbf{3}$ & 55 & 45 \\
\hline Category $\mathbf{4}$ & 8 & 11 \\
\hline Total & 103 & 115 \\
\hline
\end{tabular}

Table 3.

Frequency of diagnosis performed at each Center after scrotal explorative procedures.

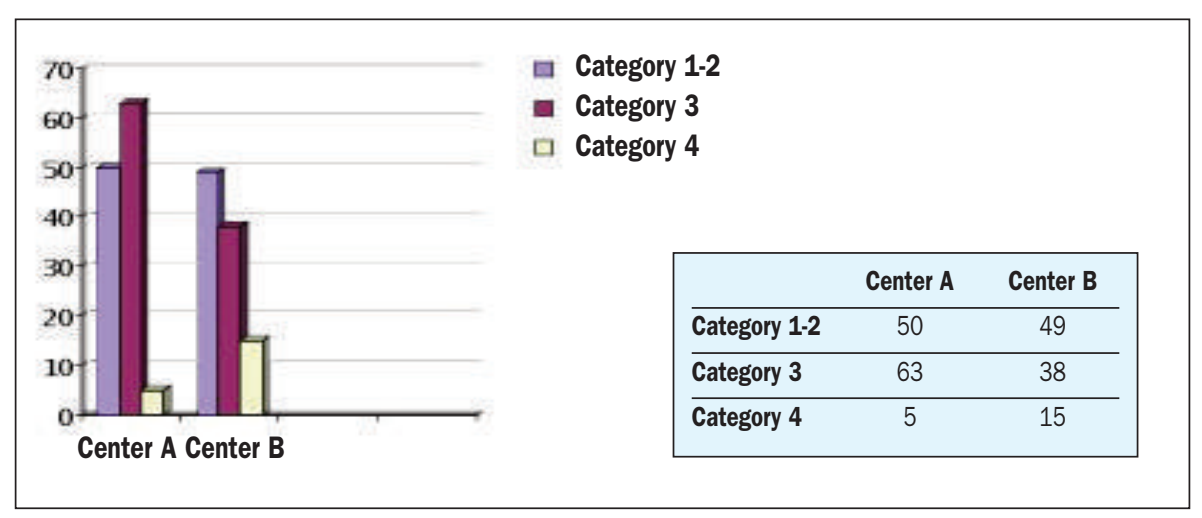

in explorative procedures and final diagnosis. In Center B distribution of type of explorative surgery diagnoses was uniform.

The chi-square test not revealed in fact association between operators and diagnosis $\left[\mathrm{X}^{2}(12, \mathrm{~N}=102)=11.97\right.$, $\mathrm{p}=.45, \mathrm{P}=.20]$. At the contrary, in center A, the association between diagnosis and operator was present $\left[\mathrm{X}^{2}(24\right.$, $\mathrm{N}=118)=88,803, \mathrm{p}<.0001$, $\mathrm{P}=.50]$.

In particular, some operators, as the number 7 , number 8 and number 10 , appeared to be more focused on a type of diagnosis than others.

Mind for the operator 10 it was de-rotations who saved the testicle. In case of operators 7 and 8 , we noted a prevalence of diagnosis of testicular appendeces torsion/necrosis.

\section{Discussion}

Testicular torsion must be diagnosed quickly and accurately. The delay of the diagno-
Table 4.

Average time elapsing between onset of acute scrotal pain and surgery in each Center of study.

\begin{tabular}{|lccc|}
\hline & Average time (hours) & Standard error & Range \\
\hline Aggregate Data & 5.55 & 0.41 & $1-72$ \\
\hline Center B & 5.75 & 0.41 & $1-24$ \\
\hline Center A & 5.39 & 0.69 & $1-72$ \\
\hline
\end{tabular}

multiple comparisons between pairs of proportions, corrected according to Bonferroni, identified as significant the difference between the Center A and B for the diagnosis represented in category 3 and $4(p=0.028)$ (Table 3$)$. The average time in hours elapsed between onset of symptoms and explorative surgery is reported in Table 4 and Figure 2, aggregated and stratified by Center. As shown in Figure 2, we noted a significant difference between spermatic cord torsion with testicular loss and all other diagnoses (all multiple contrasts, Bonferroni corrected $\mathrm{p}<0.0001)$. Testicular salvage had an average time significantly lower even than the appendix torsion/necrosis $(\mathrm{p}<0.0001)$, and others pathologies at diagnosis $(p=0.0383)$.

However, it wasn't no difference between appendix torsion/necrosis and the other pathologies diagnosed at the moment of explorative surgery. As reported in Table 5, we analyzed the correlation between surgeons involved

\section{Figure 2.}

Time (in hours) between onset of symptoms and explorative surgery stratified for diagnostic categories.

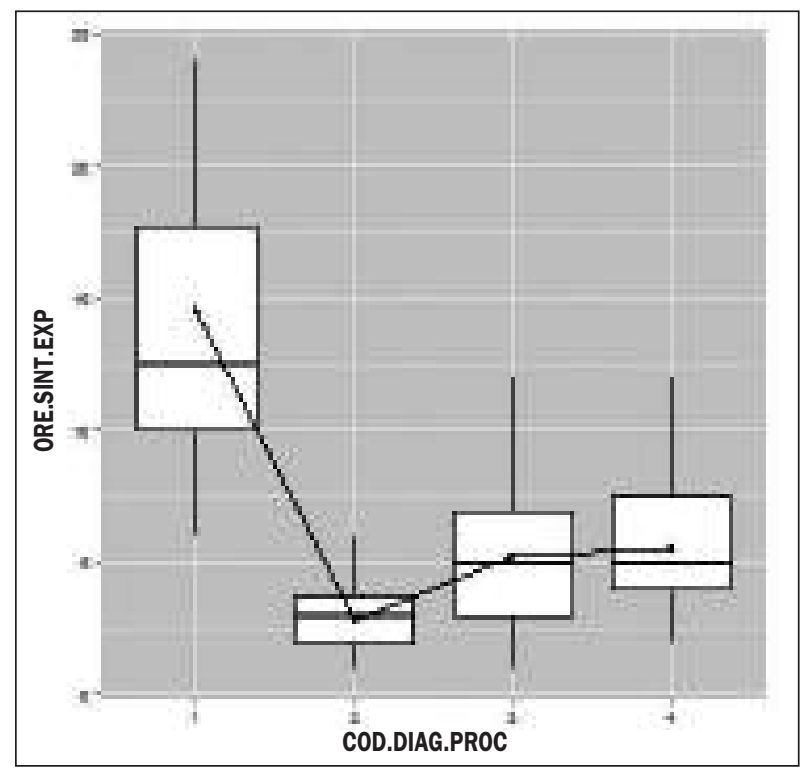

Cod. 1 Spermatic cord torsion with testicular loss

Cod. 2 Spermatic cord torsion with testicular salvage

Cod. 3 Appendix torsion/necrosis

Cod. 4 Others pathologies 
Table 5.

Surgeon stratified for Center and final diagnosis.

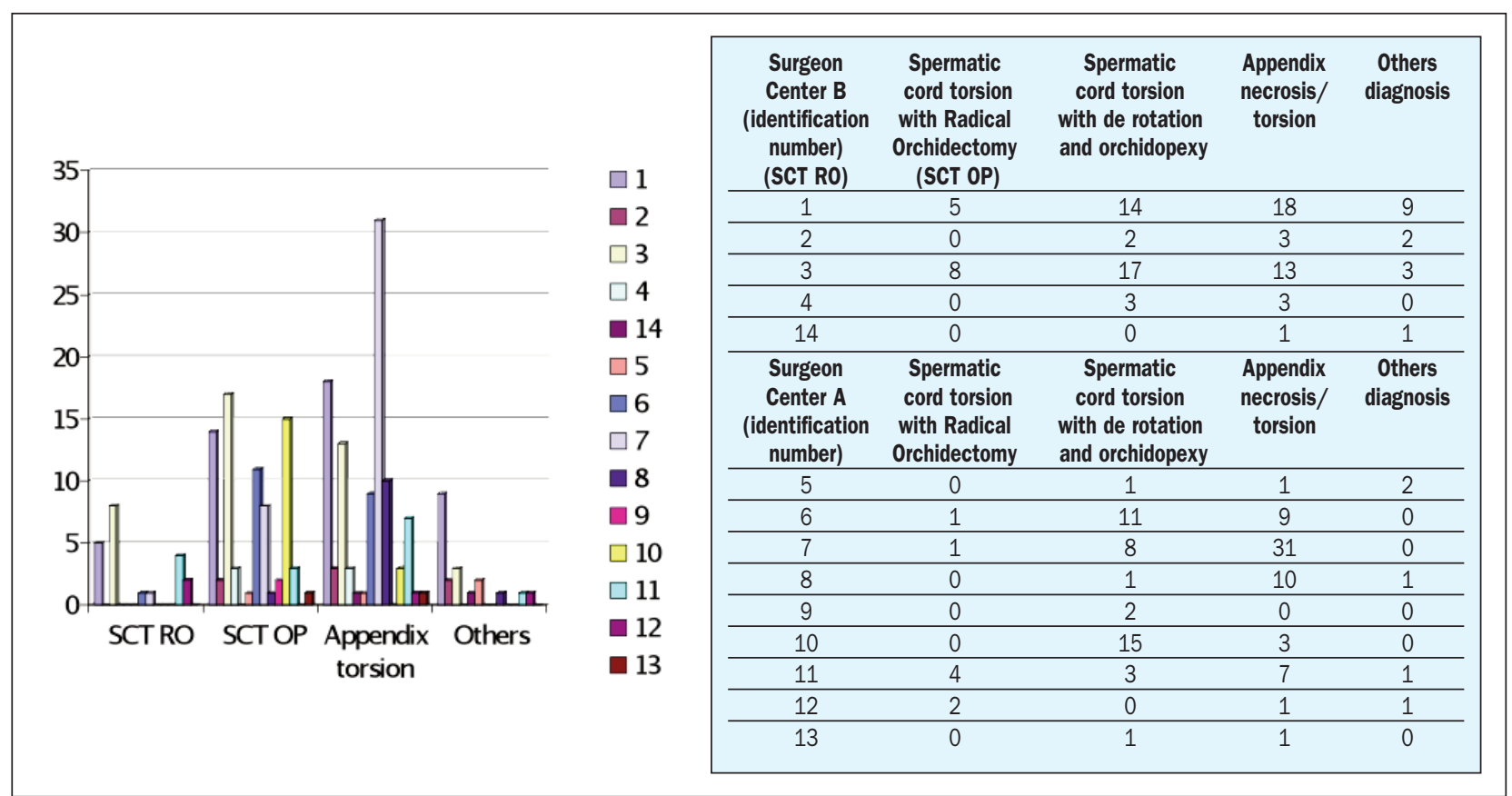

sis and the subsequent delay of surgery may lead to the loss of testicular viability and orchidectomy (1). At the same time, in case of acute scrotal pain, especially in case of very young patients, the urologist tends to follow the old maxim "if in doubt check it out". This approach may due to the risk of loss of a vital organ with medico-legal consequences.

Whereas, overdiagnosis often subjects the patients to unnecessary surgery. Acute scrotal pain may due to spermatic cord torsion in $16-42 \%$ of cases (6-7). Our analyses regarded the explorative scrotal surgeries performed in case of acute scrotal pain with the diagnostic suspicious of spermatic cord torsion. We don't have evaluated all acute scrotal pain episodes presented at the two Emergencies Departments. Thus, we are enables to define which were the effective proportions of etiologies of acute scrotal pain episodes in the population studied. Of 220 scrotal surgical explorations performed, we diagnosed spermatic cord torsion in 45\%, 78 with testicular de-rotation and subsequent orchidopexis, 21 cases with radical orchidectomy due to the loss of testicular viability. A 55\% of patients were operated although their disease could be treated conservatively. Thus, we can calculate the testicular salvage rate of our practice. The total testis salvage rate was of $78.8 \%, 84 \%$ for scrotal explorative procedures performed at Center $A$ and $73.46 \%$ for Center B. These results were higher than values reported in literature. Mushtaq et al. (8) reported a testis salvage rate of $70 \%$ and another study (9) reported this value as 62-85\%. Finally Moslemi and Kamalimotlagh (10) calculated a value of $57.5 \%$. We can explain the differences between these studies considering which are the different policies of approach to the acute scrotal pain. In case of disinformation about the importance of the prompt evaluation of acute scrotal pain or when there is a lack of access to the diagnostic procedures, as the scrotal ultrasound evaluation, may occur that explorative surgery was performed too late to avoid irreversible testicular ischemia and the consequent orchidectomy. In center A of our population study, there was a lack of application of scrotal ecocolorDoppler ultrasound study, both by consultant Urologists and Radiologists. The consultant urologist recurred frequently to explorative surgery not as therapeutic procedure but as diagnostic tool. Thus, the diagnoses of appendix torsion/necrosis were more frequent than in Center B in which ecocolorDoppler ultrasound was systematically performed. The elapsing time between onset of symptoms and explorative surgery was another critical point (11). The need of an early treatment of spermatic torsion to avoid testicular infarction is well recognized (8-12). Spermatic cord torsion reduces blood supply to the testis, which subsequently leads to hemorrhage, infarction, and necrosis. Many studies have shown that testicular infarction begins within the first 2 hours of spermatic cord torsion onset, irreversible damage occurs after 6 hours, complete infarction develops after 24 hours (13). Statistical analysis indicates that aggressive treatment performed within 6 hours of spermatic cord torsion onset has a 93\% testicular salvage rate. In contrast, only $10 \%$ of cases are resolved after 24 hours (14). In our retrospective evaluation we confirmed a significant difference between the times elapsing between onset of symptoms and spermatic cord torsion with testicular loss and all other diagnoses. Testicular salvage had an average time of 3.11 hours, significantly lower than the cases of testicular viability loss, characterized by an average elapsing time of 17.19 hours. No cases of testicular salvage after 10 hours were registered in our population study with one case of testicular loss with a time to observation of only 6 hours. In evaluation 
of acute scrotal pain, patient age may be determinant. The age distribution of testicular torsion is bimodal, with one peak in the neonatal period and the second peak around puberty (15). In our study, we had no cases of newborn patients. Mean age was of 14.46 years, with a range between 2 and 40 years. In the only patient 2 years old, a spermatic cord torsion was diagnosed, confirming that testicular viability in neonatal torsion is universally poor. In fact, one literature review of 18 case series with 284 patients found a salvage rate of about 9\% (16). In our experience, the patient age in case of appendix testicular torsion was significantly lower than the cases of spermatic cord torsion (11 vs 15 years respectively). As recently reported by Hegele et al., the patients with spermatic cord torsion had a mean age of 15.5 years, significantly older than patients suffered from appendix necrosis/torsion or epydidimo-orchitis (17). In scientific literature there is no concordance about the value of the testicular side affected as independent risk factor for testicular torsion. In 2012, in a series of 47 patients who underwent a surgical exploration for acute scrotal pain, Yu et al. (18) reported that the left side manifestation was significantly different between testicular torsion and epididymo-orchitis. We confirm this association revealing that when the affected side was the left, the probability to have a diagnosis of spermatic cord torsion was higher than in case of the right side involvement, in which a most common finding was the testicular appendix necrosis. May this association be related to an anatomical etiology? Studies on the anatomic aspects of the tunica vaginalis and the association with epididymal anatomy and its anomalies in patients with testicular torsion are scarce (19-20). We know that testicular torsion occurs due to anatomic anomalies of tunica vaginalis or epididymis that allow excessive testicular mobility inside the scrotum. Due to this excessive mobility, testis can present medial rotation that ranges from $360^{\circ}$ to $720^{\circ}$ in its own axis, which can cause interruption of the organ's vascularization (21). Favorito et al. (22), in a series of 50 testes studied during explorative surgery for acute scrotal pain, reported a normal anatomy of tunica vaginalis or epididymis at the side contralateral to the torsion in only 2 cases (4\%). Anatomic anomalies, classified previously by the same Authors (23), were founded bilaterally in the vast majority of cases. These findings stress the need for bilateral orchiopexy in cases of testicular torsion and allows us to exclude the existence of a particular anatomical cause that justifies the higher incidence of testicular torsion in the left side, bringing back the association to a mere statistical randomness. Unlike evaluated in others case series published in the literature, we analyzed the correlation between surgeons involved in explorative procedures and the type of the final diagnosis. The results obtained raise some questions. We reported in Center A an association between diagnosis and operators, in particular regarding three surgeons that appeared to be more focused on a particular diagnosis than others. In case of the strong association with a testicular de-rotation, an explication may be related to surgeon experience. Some experienced surgeons are able to clinically recognize a testicular torsion without any instrumental support (as in the case of the surgeon 10 in
Center A). However, we must consider the possibility of an untruthful diagnosis, made in order to minimize the overtreatment represented by the explorative surgery in cases without no spermatic cord torsion. Likewise, in cases of more evidence of appendix necrosis/torsion, the data could be correlated with the lack of employment of the Doppler ultrasound or with the consultant urologist experience. The scrotal exploration was used as a diagnostic tool rather than as a therapeutic tool in order to avoid testicular loss and medico-legal consequences. In these cases, the old maxime "if in doubt check it out" became the gold standard in decision making about acute scrotal pain.

\section{Conclusions}

Acute scrotum is an emergency condition that requires a prompt evaluation by physician because of the possibility of loss of the testicle. In case of spermatic cord torsion, in addition to the clinical data, patient age and left side affected may represent an independent diagnostic predicting factor. The time elapsing between onset of symptoms and explorative surgery still remain the only prognostic factor for testicular viability. The use of diagnostic instrumental tools, as the echo-color Doppler ultrasound, may aid to avoiding unnecessary explorative surgery.

\section{References}

1. Gatti JM, Murphy JP. Current Management of the Acute Scrotum, Seminars in Pediatric Surgery, Vol. 16, No. 1, 2007; pp. 58-63.

2. Wampler SM, Llanes M. Common scrotal and testicular problems. Prim Care. 2010; 37:613-26.

3. Boettcher M, Bergholz R, Krebs TF, et al. Clinical predictors of testicular torsion in children. Urology. 2012; 79:670-4.

4. Makela E, Lahdes-Vasama T, Rajakorpi H, et al. A 19-year review of paediatric patients with acute scrotum. Scandinavian Journal of Surgery. 2007; 96:62-66.

5. Dell'Atti L, Fabiani A, Marconi A, et al. Reliability of echo-colorDoppler in the differential diagnosis of the "acute scrotum". Our experience. Arch Ital Urol Androl. 2005; 77:66-8.

6. Lewis AG, Bukowski TP, Jarvis PD, et al. Evaluation of acute scrotum in the emergency department. J Pediatr Surg. 1995; 30:277-82.

7. Watkin NA, Reiger NA, Moisey CU. Is the conservative management of the acute scrotum justified on clinical grounds? Br J Urol. 1996; 78:623-7.

8. Mushtaq I, Fung M, Glasson MJ. Retrospective review of pediatric patients with acute scrotum. ANZ J Surg. 2003; 73:55-58.

9. Anderson JB, Williamson RC. Testicular torsion in Bristol: a 25year review. Br J Surg. 1988;75:988-992.

10- Moslemi KM., Kamalimotlagh S. Evaluation of acute scrotum in our consecutive operated cases: a one-center study. International Journal of General Medicine. 2014; 7:75-78.

11. Ringdahl E, Teague L. Testicular torsion. Am Fam Physician. 2006; 74:1739-43.

12. Khaleghnejad-Tabari A, Mirshermirani A, Rouzrokh M, et al. Early exploration in the management of acute scrotum in children. Iran J Pediatr. 2010; 20:466-70. 
13. Cattolica EV, Karol JB, Rankin KN, et al. High testicular salvage rate in torsion of the spermatic cord. J Urol. 1982; 128:66-8.

14. Waldert M, Klatte T, Schmidbauer J, et al. Color Doppler sonography reliably identifies testicular torsion in boys. Urology. 2010; 75:1170-4.

15 Callewaert PR, Van Kerrebroeck P. New insights into perinatal testicular torsion. Eur J Pediatr. 2010; 169:705-712.

16. Nandi B, Murphy FL. Neonatal testicular torsion: a systematic literature review. Pediatr Surg Int. 2011; 27:1037-1040.

17 Hegele A, Wappelhorst D, Varga Z, et al. Predictors of Spermatic Cord Torsion-Clinical Presentation and Intraoperative Findings Open Journal of Urology. 2011; 1:81-85.

18. Yu KJ, Wang TM, Chen HW, et al. The dilemma in the diagnosis of acute scrotum: clinical clues for differentiating between testic- ular torsion and epididymo-orchitis. Chang Gung Med J. 2012; 35:38-45.

19. Parker RM, Robison JR. Anatomy and diagnosis of torsion of the testicle. J Urol. 1971; 106:243-7.

20. Caesar RE, Kaplan GW. Incidence of the bell-clapper deformity in an autopsy series. Urology. 1994; 44:114-6.

21. Ben-Chaim J, Leibovitch I, Ramon J, et al. Etiology of acute scrotum at surgical exploration in children, adolescents and adults. Eur Urol. 1992; 21:45-7.

22. Favorito AL, Cavalcante AG, Costa WS. Anatomic aspects of epididymis and tunica vaginalis in patients with testicular torsion Int Braz J Urol. 2004; 30:420-424.

23. Favorito LA, Sampaio FJ. Anatomical relationships between testis and epididymis during the fetal period in humans (10-36 weeks postconception). Eur Urol. 1998; 33:121-3.

\section{Correspondence}

Andrea Fabiani, MD (Corresponding Author)

andreadoc1@libero.it

Fabrizio Fioretti, MD PhD

fa.fioretti@libero.it

Valentina Maurelli, MD

valentinamaurelli@hotmail.it

Francesco Catanzariti MD

frenzis83@gmail.com

Lucilla Servi, MD

lucilla.servi@sanita.marche.it

Gabriele Mammana, MD

gabriele.mammana@sanita.marche.it

Surgery Dpt, Section of Urology, ASUR Marche Area Vasta 3

Macerata Hospital, Macerata, Italy

Massimo Calabrese, $M D$

calmas@alice.it

Operative Unit of Urology

SS. Filippo e Nicola Hospital, Avezzano (AQ), Italy

Alessandra Filosa, MD PhD

alessandrafilosa@yahoo.it

Section of Pathological Anatomy, Department of Clinical Pathology,

Area Vasta 3, ASUR Marche, Macerata Hospital, Macerata, Italy

Michele Scandola, PhD

michele.scandola@univr.it

Departement of Human Sciences, University of Verona -

IRCCS Santa Lucia Foundation, Rome,

Departement of Psychology, University of Rome "Sapienza", Rome, Italy

Stefano Noventa, $\mathrm{PhD}$

stefano.noventa@univr.it

Center for Assessment, University of Verona, Verona, Italy

Flavia Tombolini MD, Urology Resident

flavia.tombolini@gmail.com

Urologic Clinic, Polytechnic University of Marche Region, Italy 